\title{
A PeRCEPÇÃo de MULHERES SOBRE ATENÇÃo PRÉ-NATAL EM UMA UNIDADE BÁSICA DE SAÚDE
}

\author{
Women's Perception About Pre-Conception Attention \\ in a Basic Health Unit \\ La Percepción de Muj eres Sobre Atención Pre-Natal \\ en una Unidad Básica de Salud
}

\author{
Maria Celeste Landerdahl \\ Fernanda Bheregaray Cabral
}

\author{
Lúcia Beatriz Ressel \\ Mariam de Oliveira Gonçalves
}

Fernanda Badineli Martins

\section{Resumo}

Pesquisa com objetivo de conhecer a percepção de gestantes a respeito da consulta de pré-natal realizada por docentes e acadêmicos do Curso de Enfermagem da Universidade Federal de Santa Maria em uma Unidade Básica de Saúde (UBS) do município. Foram sujeitos da pesquisa dez puérperas que realizaram consultas de enfermagem na UBS, no período de julho de 2003 e agosto de 2004. A obtenção das informações foi realizada por meio de entrevistas semi-estruturadas. As respostas acusam, dentre outros dados, a consulta de enfermagem à gestante como espaço educativo do qual fazem parte também seus familiares, bem como o vínculo estabelecido entre profissional e gestante/família. Por outro lado, apontam para a necessidade de maior privacidade para o atendimento e criticam a troca eventual de profissionais/ docentes nas consultas. Nesse sentido, o estudo tem auxiliado no redirecionamento da atenção à gestante, de forma que venha ao encontro de suas necessidades e expectativas.

Palavras-chave: Pré-natal. Gestante. Cuidado. Enfermagem.

\begin{abstract}
This research aims to know the perception of pregnant women concerning to the prenatal appointment carried out by professors and pupils of the Nursing Course of the Federal University of Santa Maria in a city Basic Health Unit. Ten pregnant women who had nursing appointments in a Basic Health Unit from July 2003 until August 2004 were subjects of the research. Semi-structured interviews have been carried out in order to obtain the answers. The answers state, among other data, the nursing appointment as an educative space where all her family members also participate as well as a connection between the professional and the woman/family. On the other hand, the answers also show the need of a bigger privacy during the appointment and criticize possible changes of professionals or professors in these appointments. Thus, this study has helped in changing the atention provided to the pregnant women so that it reaches their necessities and expectations.
\end{abstract}

\section{Resumen}

Esta investigación tubo como objetivo conocer la percepción de gestantes respecto a la consulta de prenatal realizada por docentes y académicos del Curso de Enfermeros de la Universidad Federal de Santa María en una Unidad Básica de Salud del municipio. Fueron sujetos de la investigación diez puérperas que realizaron consultas con los enfermeros en la UBS, en el período de julio de 2003 y agosto de 2004. La obtención de las informaciones fue realizada por medio de entrevistas semiestructuradas. Las respuestas acusan, entre otros datos la consulta con enfermeros, a la gestante como espacio educativo del cual hacen parte también sus familiares; bien como el vínculo establecido entre profesional y gestante/familia. Por otro lado, apuntan para la necesidad de mayor privacidad para el atendimiento y critican el cambio eventual de profesionales/ docentes en las consultas. En ese sentido, el estudio ha auxiliado en el redireccionamiento de la atención a la gestante, de manera que venga al encuentro de sus necesidades y expectativas.

\section{Keywords:}

Prenatal. Pregnant Woman. Care. Nursing.
Palabras clave:

Prenatal. Gestante. Cuidado. Enfermería. 


\section{INTRODUÇÃO}

A gestação, embora constituindo um fenômeno fisiológico que na maior parte dos casos tem sua evolução sem intercorrências, requer cuidados especiais mediante assistência pré-natal. Essa, por sua vez, tem como objetivo principal acolher e acompanhar a mulher durante sua gestação, período caracterizado por mudanças físicas e emocionais vivenciado de forma distinta pelas gestantes. No entanto, as consultas médicas de pré-natal no serviço público são muito rápidas, fazendo com que possíveis anormalidades não sejam percebidas e impedindo que as mulheres não manifestem suas queixas, dúvidas e medos intrínsecos à gravidez ${ }^{1}$. Esse fato tem motivado a preocupação de gestores de saúde, tendo em vista que se relaciona aos altos índices de mortalidade materna no Brasil, o qual, em 2001, foi de 74.5 óbitos por 100.000 nascidos vivos ${ }^{2}$. Em comparação com países desenvolvidos, cuja taxa é de 9 óbitos por 100.000 nascidos vivos, percebese que essa cifra é muito alta ${ }^{3}$.

Ante tais dados, cabe aos profissionais de saúde uma reflexão acerca da assistência prestada às gestantes, bem como buscar subsídios para o planejamento, implementação e avaliação da assistência pré-natal que alcancem melhores níveis de qualidade. Em consonância ao exposto, a atenção ao pré-natal, parto e puerpério está muito interligada, e a impossibilidade de acesso às informações, em qualquer desses períodos, fragiliza a assistência, expondo a mulher a risco de vida ${ }^{4}$.

A atenção pré-natal objetiva acolher a mulher desde o início da gravidez, buscando assegurar, ao seu término, o nascimento de uma criança saudável e a garantia do bem-estar materno e neonatal ${ }^{5}$.

É importante enfatizar que a atenção pré-natal, por não envolver procedimentos complexos, favorece a interação entre o profissional e a gestante e sua família. Essa interação contribui para que a gestante mantenha vínculo com o serviço de saúde durante todo o período gestacional, reduzindo consideravelmente os riscos de intercorrências obstétricas. Além disso, a assistência gestacional, quando mediada por diálogo e respeito entre profissionais de saúde e gestantes, representa o primeiro passo para o parto humanizado.

$\mathrm{Na}$ tentativa de contribuir com a qualidade da assistência a essa clientela, o Curso de Enfermagem da Universidade Federal de Santa Maria (UFSM) vem, desde 1993, implementando Consultas de Enfermagem às gestantes na Unidade Sanitária Kennedy, Santa Maria (RS), mediante um projeto de ensino, pesquisa e extensão em parceria com a Secretaria de Município da Saúde. Esse projeto tem como objetivo contribuir na efetivação do Sistema Único de Saúde, bem como na reorientação do caráter de formação dos acadêmicos de Enfermagem, de modo que venha a ser condizente com as diretrizes apontadas pelo modelo de saúde em construção no país.

As consultas de enfermagem no pré-natal realizadas na referida unidade são intercaladas com consultas médicas e se restringem às gestantes sem risco obstétrico. Têm seu foco centrado nos aspectos educativos, os quais possibilitam às gestantes espaços para expressarem seus medos, angústias, fantasias e dúvidas sobre as modificações que estão acontecendo com o próprio corpo, permitindo esclarecimentos mediante orientações pertinentes ao ciclo gravídico-puerperal. Sob esse viés, a dimensão educativa objetiva contribuir com o acréscimo de informações que as mulheres possuem sobre seu corpo, valorizando sua experiência de vida e contribuindo de forma relevante para a busca de sua autonomia. Para isso, as ações educativas devem superar o modelo biomédico de modo que valorizem as reais necessidades da gestante, considerando sempre seu contexto de vida/saúde.

Com vistas à redução da morbimortalidade materna e fetal, durante as consultas de enfermagem - além da escuta e do diálogo estabelecido com a gestante - são realizados procedimentos técnicos de rotina, tais como medida da pressão arterial, peso, cálculo da idade gestacional, ausculta de batimentos cardíacos fetais e medida da altura uterina, que são registrados no histórico de enfermagem e na carteira da gestante. Fica evidente, assim, que a assistência pré-natal almejada com essa atividade na unidade básica referida, evidencia nossa preocupação com o bem-estar físico e mental do binômio mãe e filho.

No entanto, com o desenvolvimento do trabalho, passamos a perceber a necessidade de saber se essa atividade estava em consonância com as expectativas e necessidades das gestantes assistidas, constituindo, desta forma, um primeiro passo no processo de avaliação das consultas de enfermagem na unidade. Para tanto, com o envolvimento de acadêmicas do Curso de Graduação em Enfermagem/UFSM, realizamos a pesquisa, objeto do presente relato, a qual teve como objetivo conhecer a percepção das gestantes a respeito da consulta de pré-natal realizada por docentes e acadêmicos do Curso de Enfermagem na Unidade Sanitária Kennedy, em Santa Maria (RS).

\section{METODOLOGIA}

A presente investigação delineou-se como uma pesquisa descritiva do tipo exploratória, com abordagem qualitativa. Foi desenvolvida em uma Unidade Básica de Saúde, local de aulas práticas e estágio supervisionado do Curso de Enfermagem da UFSM, onde são realizadas ações de atenção à saúde em sintonia com os preceitos do novo modelo assistencial legalmente assegurado na Constituição Federal de 1988.

Como sujeitos desta pesquisa, elegeram-se dez mulheres em período de puerpério, que realizaram sua assistência pré-natal mediante consultas de enfermagem na UBS, no período de julho de 2003 e agosto de 2004, e que aceitaram participar do estudo.

Para a obtenção de dados foi utilizada a entrevista semiestruturada, individual, com roteiro específico, a qual foi realizada e gravada durante visita domiciliar à puérpera, com duração média de 45 minutos mediante agendamento prévio. As informações gravadas foram transcritas na íntegra para, após, serem categorizadas e analisadas. Nenhuma informante demonstrou objeção ao uso do gravador. Foram utilizados, 
Serve para a gente cuidar da saúde da gente, evitar problemas. M6

nesta etapa, o formulário de registro das consultas de enfermagem no pré-natal, a fim de acessar os dados de identificação e de acompanhamento do pré-natal.

Buscando uma condução ética para este estudo, embasamos nossa atuação na Resolução n 196/96, publicada no Diário Oficial da União em 10/10/96, que institui as Normas de Pesquisa em Saúde com seres humanos. Assim, antes de iniciar a coleta de dados, cada participante autorizou, por meio do Termo de Consentimento Livre e Esclarecido, seu envolvimento no presente estudo, sendo assegurada a validação de seu depoimento ao final de cada entrevista, a partir da escuta da fita cassete; o direito de participar ou retirar-se da pesquisa; de informação quanto ao objetivo da pesquisa, proteção e guarda do material gravado, bem como uso deste material pelas pesquisadoras; e de resguardo da sua identificação. Em respeito a esse princípio, as mulheres foram identificadas com a letra "M" e numeradas de 1 a 10.

Após a coleta, os dados foram analisados em consonância às orientações de estudo ${ }^{6}$ sobre pesquisa com abordagem qualitativa. Neste sentido, foram realizadas leituras sucessivas dos depoimentos, buscando uma impregnação das informações aí contidas; estas foram agrupadas e categorizadas de acordo com as afinidades temáticas; e, após a classificação e agregação dos dados, foi realizada a interpretação dos mesmos e a comparação com a literatura espećíica, bem como foram feitas inferências que esclareceram os achados da pesquisa.

\section{ANÁLISE E DISCUSSÃO DOS DADOS}

\section{0 perfil das informantes}

Todas as mulheres eram casadas ou viviam com companheiros em união estável e residiam na área de abrangência da UBS. A idade das informantes variou entre 16 e 34 anos. Com relação ao grau de escolaridade, sete tinham o ensino fundamental incompleto; uma, o ensino fundamental completo; e duas, o ensino médio incompleto. A ocupação das entrevistadas foi assim referida: cinco eram "do lar", uma era balconista e quatro realizavam trabalho como domésticas em casas de família, sendo que uma dessas estava desempregada no momento da obtenção de dados. A renda familiar variou de 2 a 4 salários mínimos. Uma mulher referiu não ter renda familiar no momento em razão de estar desempregada, assim como seu marido.

\section{A fala das informantes}

Em relação à primeira categoria, compreensão acerca da assistência pré-natal, todas as respondentes entendem que constitui um momento de aprendizado, o qual torna oportuno o maior conhecimento a respeito do processo gravídico-puerperal, além de possibilitar a prevenção de problemas tanto para mãe quanto para o concepto, conforme aparece nos relatos.

Tenho um monte de filhos, tenho experiência, mas sempre tenho dúvidas e alguma coisa para aprender. É porque acho que cada gravidez é diferente da outra. M5

Embora admitindo vivências anteriores, que trouxeram experiência, a informante entende que cada gravidez é singular, necessitando, portanto, de aprendizado e cuidado específico.
Aqui a informante expressa que a atenção no pré-natal também pode representar momento de aprendizado para sua saúde como um todo, inclusive fora do ciclo gravídico-puerperal. Nesse sentido, a assistência pré-natal se reveste de uma importância maior ainda, uma vez que para muitas mulheres esse é um dos poucos momentos de sua vida em que mantém contato com os serviços de saúde.

Pensa-se, neste sentido, que compreender a importância do pré-natal para essas mulheres permite entender o significado deste cuidado para elas, auxiliando no direcionamento de nossa assistência. Como refere estudo da área da Antropologia ${ }^{7}$, as pessoas são extremamente variáveis e sujeitas a inúmeras influências. Expressam-se mediante símbolos e se organizam a partir de concepções na busca de significados. Como todos os acontecimentos têm significados específicos, ou seja, eles simplesmente não só acontecem, mas significam algo às pessoas envolvidas, é fundamental buscar a interpretação cultural deles para desenvolver um cuidado mais efetivo. E é por meio da compreensão da visão de mundo do "outro" que tornamos oportuno expressar diferenças e singularidades que precisam ser abarcadas em nosso cuidado.

Quando questionadas sobre $o$ que pensam os familiares sobre a assistência pré-natal, nove mulheres responderam que a família considera importante esse espaço de atenção à saúde.

O pessoal aqui em casa gostava que eu ia, eles acham importante o pré-natal. M1

Meus familiares acham bem importante. M6

De acordo com pesquisa realizada na área da Enfermagem 8:165 "há intrincada relação entre as crenças, valores e costumes que são desenvolvidos no cotidiano pelas pessoas e a forma como elas se expressam nas situações de saúde ou doença". Com isso, é possível inferir que a importância dada pela família à realização do pré-natal direciona o caminho, as decisões e ações a serem seguidos pela gestante, uma vez que suas concepções e entendimentos dos eventos de saúde e doença são balizados pelas crenças e valores socializados na família.

Neste sentido, um estudo referente ao cuidado cultural à mulher grávida ${ }^{9}$ salienta que a gestação é uma experiência familiar; logo, o cuidado prestado deve envolver toda família e buscar o sentido cultural dela para tal vivência. Isso ficou evidente quando as gestantes referiram que o conhecimento adquirido nas consultas de enfermagem era socializado na família. Percebe-se que, além de fortalecer a importância da realização do pré-natal às gestantes, os familiares participavam direta e indiretamente do evento.

... o meu marido ficava sempre perguntando, queria saber se eu tinha falado sobre o que acontecia comigo. M10

Em algumas ocasiões, acompanhavam as gestantes nas consultas, em outras, socializavam as informações adquiridas nestes momentos e buscavam saber como estava a saúde da gestante, bem como o desenvolvimento do feto. Dentre os 
familiares, foi citada a participação do marido, dos filhos, da mãe e irmãos da gestante.

Ah... eu sempre ia com a mãe, com minha irmã ou com meu marido, quando ele podia né. M1

Algumas vezes trouxe os meus dois filhos mais velhos, o meu marido não podia ir, mas se interessava pelo que acontecia lá. M6

Os maridos participavam mais indiretamente, não podendo acompanhar muitas consultas devido ao horário de trabalho. No entanto, conforme a fala anterior, as informantes destacavam seu interesse sobre o que estava acontecendo. Isso é congruente com estudo antropológico ${ }^{10}$, que afirma 0 envolvimento físico e emocional masculino nos eventos da gravidez e do parto de seus filhos; porém, a intensidade e a manifestação ocorrem de acordo com a cultura local. Nesta linha, percebemos a importância do entendimento de que a gestação, além de ser um processo biológico, é também um processo social e cultural. Cada mulher e sua família irá vivenciar esta experiência de forma singular dentro de sua unidade coletiva. Esta compreensão redireciona a assistência no prénatal e as práticas de saúde, exigindo a atenção não só ao binômio materno-fetal, construído em paradigmas biologicistas, mas ao núcleo familiar e social a que pertence esta gestante. Isto vem ao encontro das diretrizes preconizadas pelo Ministério da Saúde atualmente, nas políticas da atenção à saúde da mulher e de humanização ao pré-natal e ao parto, que trazem em seu bojo o enfoque cultural ao atendimento às pessoas, que deverá ser incorporado aos processos de sensibilização e capacitação para humanização das práticas de saúde. Uma depoente, no entanto, mencionou que os familiares não consideram relevante $\mathrm{a}$ atenção à mulher no pré-natal.

A família acha que é bobagem, uma perda de tempo, mas eu fiz dos outros e gostei. M5

Nota-se nesta fala que, embora sua família não considere necessário e importante a assistência pré-natal, a própria gestante tem desenvolvido novos valores culturais em relação à gestação, opondo-se a antigos conceitos de familiares. É possível perceber que a cultura é dinâmica e mesmo dentro do grupo social as mudanças ocorrem, revelando espaços para as diferenças coexistirem, às vezes com conflitos, mas aceitando o pluralismo cultural e se opondo à rigidez e ao reducionismo cultural ${ }^{11,12}$.

Ao serem questionadas a respeito do tempo de duração das consultas, nove mulheres referiram ser suficiente o tempo médio de 50 minutos para a primeira consulta e 30 para os retornos, conforme os depoimentos comprovam.

...eu acho que era bom, a gente conversava bastante, depois fazia o exame, via a pressão, escutava o coração do bebê... eu gostava muito de ir conversar com vocês. M5

...acho ótimo... não fazem nada correndo para irem embora, ficam conversando, são atenciosas, é dez. ...era ótimo, esclarecia o que não conseguia com o médico; vocês fazem a gente entender. M7
Nota-se nas falas, que a avaliação positiva do tempo reservado às consultas está em íntima consonância com a satisfação das mulheres em relação à qualidade da consulta. Ao referirem-se às consultas como uma "conversa", fica evidente, também, a relação horizontal que se busca no momento da consulta de enfermagem no pré-natal na unidade sanitária. A esse respeito, o Ministério da Saúde enfatiza em suas recomendações ${ }^{1: 10}$ que a humanização da assistência à gestante requer relações menos desiguais e menos autoritárias, na medida em que o profissional, em vez de assumir o comando da situação, passa a adotar condutas que busquem o bem estar da gestante.

Uma respondente identificada como M2 acusou que o tempo da consulta era insuficiente. No entanto, sua queixa não tinha relação com suas consultas, mas ao fato de que precisava esperar para ser atendida.

De fato, não é incomum ocorrer atraso em virtude de situações não previstas. Uma delas ocorre quando a gestante procura o serviço, sem agendamento, em razão de alguma dúvida, ansiedade ou queixa importante; essas situações exigem nossa atenção no sentido de acolher a gestante, sendo necessário, muitas vezes, realizar um exame físico com vistas a tranqüilizá-la ou como subsídio para proceder algum encaminhamento importante. Outras motivações que justificam o atraso no atendimento cotidiano dessa atividade dizem respeito a fatores específicos às gestantes, como faixa etária em que elas se encontram, experiências anteriores, número de filhos, problemas familiares, dentre outros.

Todas essas situações possibilitam, pela relação de interação que se estabelece na consulta, que a gestante se sinta à vontade para abordar temas que venham ao encontro de suas necessidades. É importante lembrar, ainda, que é inerente a todo o campo de aula prática acadêmica a utilização de um tempo maior no atendimento, tendo em vista o processo educativo que aí se efetiva. Algumas mulheres conseguem compreender essa realidade. É o que fica evidente na fala de M8 que, juntamente com outra respondente, apontou atraso ao ser questionada sobre o tempo de espera para o atendimento.

...sempre fui atendida no horário marcado, só quando tinha alguma gestante que passava mal, aí atrasava um pouco; mas a gente entende né. Depois vocês explicavam direitinho o porquê do atraso. Isso é legal, dá pra perceber o interesse e o comprometimento de vocês com as gestantes. M8

Além de compreender a razão do atraso, M8 percebe 0 respeito e compromisso que os envolvidos com a atividade reservam às gestantes, princípios fundamentais que devem pautar a atenção à saúde da população em geral e, em especial à gestante. As demais respondentes referiram que eram atendidas no horário agendado.

Quando questionadas em relação ao acesso ao agendamento para as consultas, todas responderam que não havia problemas, pois para a primeira consulta 0 agendamento era realizado na própria sala de atendimentos pela secretária, enfermeira ou acadêmicos de enfermagem, enquanto que os retornos eram agendados no final de cada consulta. 
Quanto à categoria linguagem utilizada nas consultas, todas acusaram compreender o que era compartilhado nas consultas de enfermagem. Referiram também que, quando era necessário, solicitavam maiores explicações, o que evidencia que a gestante é co-partícipe na condução do processo que vive ${ }^{13}$.

Acho bem bom o jeito que vocês falam e explicam as coisas para a gente, porque às vezes os médicos falavam umas coisas que, nossa, eu nunca vi, e como não tinha tempo de perguntar eu até anotava algumas coisas e falava com vocês. M6

Entendia tudo que as gurias falavam, o que não entendia eu perguntava. M10

Os depoimentos, ao mesmo tempo em que expressam a importância da aproximação às falas das classes populares, revelam, novamente, mesmo que de forma subjacente, a interação que se estabelece entre os envolvidos, no qual a liberdade e o vínculo de confiança é evidente. Mostra também a consulta de enfermagem como importante instrumento de educação em saúde, no qual o profissional deve abandonar a postura de onipotência, mediando o saber científico com o popular. Reforçando tal compreensão, estudo de referência na Pedagogia ${ }^{14: 29}$ assegura que:

...não podemos nos colocar na posição de ser superior que ensina um grupo de ignorantes, mas sim na posição humilde daquele que comunica um saber relativo a outros que possuem outro saber relativo.

Com relação ao número de acadêmicos presentes na sala no momento da consulta, nove respondentes manifestaram que, embora em alguns momentos o número de acadêmicos fosse grande, esse fato não interferia na qualidade da consulta. Ao mesmo tempo, demonstraram, em sua maioria, a compreensão de que o espaço é oferecido como campo prático do Curso de Enfermagem da UFSM, sendo, desta forma, momento de aprendizado para os acadêmicos de enfermagem.

Eu me sentia tão à vontade que não via problema nenhum, as pessoas que ficavam ali me deixavam bem à vontade. M5

Foibom, as gurias aprendeme eu também, émuito bom. M4

É importante ressaltar que desde a primeira consulta procuramos estabelecer um vínculo com a gestante/familiares. Ao nos apresentarmos e explicarmos a dinâmica das consultas, bem como o motivo da participação dos alunos, criamos um clima de receptividade, liberdade e respeito que balizam nossos encontros. Acreditamos que essa postura tem sido facilitadora para o entendimento e boa aceitação dos acadêmicos nas consultas; ao mesmo tempo vem ao encontro de pressupostos de humanização recomendados em diretrizes de políticas públicas de atenção à saúde da mulher quando defende o acolhimento e o respeito à gestante no serviço de saúde.

Dentre essas mulheres, no entanto, duas manifestaram que o movimento de entrada e saída da sala era muito grande e que isso interferia muitas vezes na conversa estabelecida com a enfermeira e seus alunos. Isso acontece porque a sala onde é realizada a consulta é a mesma onde são desenvolvidas atividades relacionadas ao planejamento familiar, porém em horário diverso das consultas. Assim, muitas mulheres

que recorrem a tais atividades sem agendamento recebem, igualmente, a atenção da secretária, mesmo que somente para esclarecimentos e/ou encaminhamentos para o cadastro em outro horário. Essa situação parece constranger as mulheres.

O número de alunos não incomoda, não gostava do entrae-sai da sala que alguns dias tinha. A gente tava à vontade falando ali certas coisas, então chegava alguém estranho, a gente já se retrancava. M1

No depoimento de M1 fica evidente que o movimento de pessoas entrando na sala, embora seja mantido um biombo separando os dois ambientes, tira a privacidade e naturalidade do momento, podendo comprometer a interação afetiva e 0 vínculo de confiança estabelecido entre os envolvidos durante o processo do cuidado à gestante, fatores fundamentais para a qualidade da atenção pré-natal.

Informações com esse teor têm sido balizadoras das nossas ações com as mulheres, reforçando a importância da participação da comunidade nos rumos da saúde pública. Desta forma, alguns cuidados vêm sendo tomados pela equipe no sentido de oferecer um ambiente mais adequado ao atendimento da gestante.

A troca de profissionais nas consultas foi apontada por sete respondentes, mesmo que em alguns momentos de forma sutil, como um fator que pode interferir na qualidade da atenção no prénatal. Alegam que, quando não são assistidas pela mesma profissional em todas as consultas, são repetidas muitas informações.

Eu acredito que isso não interfere, só acontece que, às vezes tem que repetir as coisas... M6

Seria bom que começassem e fossem até o final. Quando troca, tu tem que falar algumas coisas de novo... mas não interferiu no pré-natal. M5

É importante esclarecer que a troca de enfermeiras/ docentes nas consultas de enfermagem na unidade básica em questão ocorre no período de férias letivas, quando acontecem substituições temporárias, a fim de manter a continuidade do atendimento. Como esse serviço tem sido realizado, exclusivamente, por docentes da universidade, sem a parceria efetiva das enfermeiras da unidade básica até o presente momento, essa lacuna se revela.

Essa situação tem sido motivo de preocupação e exige mudanças que dependem de fatores diversos, dentre eles a compreensão urgente por parte de gestores municipais e profissionais da área da saúde que atuam neste serviço a respeito da importância da integração ensino/serviço como uma das molas propulsoras para a efetiva qualidade da assistência em qualquer nível de atenção à saúde.

Tais depoimentos, todavia, não parecem afetar significativamente a interação e o vínculo entre profissional, acadêmicos e usuários do serviço. Isso ficou muito claro quando os sujeitos da pesquisa responderam a respeito de como se sentiam nas consultas de prénatal de enfermagem e sua relação com a enfermeira e acadêmicos. 
Ali eu encontrava atenção. Digamos assim, uma experiência de mãe e de irmã que elas tinham pra me passar. Cada consulta que chegava eu ficava muito contente, muito faceira.. me sentia em casa, ali eu tinha carinho. M1

0 depoimento reforça a importância da interação gestante-profissionais de saúde. Estes, por sua vez devem ter ciência de seu papel como coadjuvantes dessa experiência, colocando sua sensibilidade e conhecimento a serviço do bem-estar da gestante/familiares.

Quando questionadas de que forma as orientações recebidas no pré-natal de enfermagem influenciaram no momento do parto, todas as mulheres foram enfáticas em afirmar positivamente.

Vocês me passavam muita segurança... o momento do parto foi maravilhoso, fiquei calma... estava bem orientada sobre como cuidar de mim e do bebê. M7

... até as enfermeiras e o médico me disseram que eu estava bem calma, e eu falava que eu sabia que eles estavam ali para me ajudar... eu acho que o pré-natal também serve pra isso né, pra ensinar a gente e deixar a gente mais calma na hora do parto. M8

Sim, fiquei calma, pensava no jeito de respirar, que eu tinha que ajudar fazendo força pro meu nenê sair mais fácil, foi um ótimo parto. M6

As falas denotam a participação ativa e consciente das gestantes no processo de parir, evidenciando a ênfase dada, durante a atenção pré-natal, ao seu importante papel de sujeito no parto e nascimento. Acreditamos que tal postura somente é possível no momento em que a gestante tem conhecimento de seu corpo e de suas transformações durante o processo gravídico-puerperal. A compreensão sobre o contexto históricoestrutural onde se insere a mulher/gestante também se faz importante e pode contribuir na conscientização da gestante, dentre outras coisas, em relação a sua autonomia no parto.

Ao serem argüidas sobre sugestões para melhorar a qualidade da atenção, sete respondentes referiram que nada precisava ser mudado. Uma mulher referiu que seria importante respeitar a pontualidade nas consultas, e duas pensam que, diminuindo o movimento de pessoas entrando na sala, elas se sentirão mais à vontade, conforme já foi referido anteriormente. Tais fatores podem ser considerados, evidentemente, como sugestões para o alcance da qualidade do serviço.

\section{Referências}

1. Ministério da Saúde (BR). Parto, aborto e puerpério: assistência humanizada à mulher. Brasília (DF); 2001.

2. Ministério da Saúde (BR). Política Nacional de Atenção Integral à Saúde da Mulher: princípios e diretrizes. Brasília (DF); 2004.

3. Ministério da Saúde (BR). Urgências e emergências maternas. Brasília (DF): Febrasgo; 2000.

\section{CONSIDERAÇÕES FINAIS}

Ao final desta pesquisa vale destacar os pontos fortes e fracos revelados nas falas das informantes. Elas associam a atenção pré-natal a um momento educativo; sentem-se satisfeitas em relação à qualidade da consulta, no sentido de acolhimento, respeito e compromisso que os envolvidos com a atividade reservam a elas; compreendem as orientações compartilhadas nas consultas de enfermagem e sentem-se à vontade para solicitar maiores explicações, o que evidencia a interação e confiança estabelecidas, e consideram-se apoiadas na relação com a enfermeira e com os acadêmicos. Por outro lado, apontaram a necessidade de maior privacidade nas consultas e solicitam que 0 pré-natal seja acompanhado pelo mesmo profissional.

0 estudo reforçou a necessidade de a atenção pré-natal envolver a família da gestante e seu grupo social, uma vez que a gestação é entendida como um evento biológico e social, uma experiência familiar, portanto. Depreende-se disso, que todos são atores sociais neste acontecimento, e que sua bagagem cultural implica nos encaminhamentos a serem determinados em cada situação específica. Isso possibilita a enfermeira redirecionar seu cuidado, singularizando-o.

Salientou também a necessidade urgente de compreensão por parte de gestores e profissionais da área da saúde que atuam neste serviço a respeito da importância da integração ensino/serviço como forma de qualificar a assistência em qualquer nível de atenção à saúde.

Ao mesmo tempo, possibilitou iniciarmos um processo de avaliação do serviço, apontando para os aspectos que necessitam de reorientação, bem como reforçando aqueles que estão em sintonia com as expectativas das usuárias. Desta forma, o estudo não se encerra com esta análise, sendo para nós motivador de reconstruções permanentes na busca pela humanização da atenção à saúde da mulher em todo o seu ciclo vital. Em relação ao processo de gestar e parir, revela-se um desafio, uma vez que representa o resgate da autonomia feminina. Confirma-se, também, que todas essas demandas exigem dos profissionais envolvidos com a saúde da mulher a busca por referenciais éticos e humanísticos que estejam em consonância com suas expectativas e necessidades.

Nessa perspectiva, é relevante darmos seguimento à investigação iniciada, objetivando conhecer a percepção que familiares e profissionais do serviço têm a respeito da consulta de pré-natal realizada por enfermeiros na referida unidade básica. Sem dúvida novos elementos serão pontuados, possibilitando melhor adequação às necessidades da gestante, ao mesmo tempo em que proporcionarão visibilidade ao trabalho do enfermeiro no cenário da saúde pública, no nível da atenção básica.

4. Tanaka ACA. Maternidade: dilema entre nascimento e morte. São Paulo(SP): Hucitec; 1995.

5. Cabral FB, Ressel LB, Landerdahl MC. Consulta de enfermagem: estratégia de abordagem à gestante na perspectiva de gênero. Rev Esc Enferm Anna Nery 2005 dez; 9 (3): 459-65.

6. Minayo MCS. 0 desafio do conhecimento: pesquisa qualitativa em saúde. $8^{\text {a }}$ ed. Paulo(SP): Hucitec; 2004.

7. Geertz C. Ainterpretação das culturas. Rio de Janeiro(RJ): LTC;1989. 


\section{Sobre as Autoras}

saúde em comunidade rural. In: Gonzales RMB Beck CLC Denardin ML. Cenários de cuidado: aplicação de teorias de enfermagem. Santa Maria (RS): Pallotti; 1999.

9. Baruffi LM. 0 cuidado cultural à mulher na gestação. Passo Fundo (RS): UPF; 2004.

10. Helman CG. Cultura, saúde e doença. $4^{\text {a }}$ ed. Porto Alegre (RS): Artmed; 2003

11. Featherstone MO. 0 desmanche da cultura: globalização, pósmodernismo e identidade. São Paulo(SP): Studio Nobel; 1997.

12. Robertson R. Globalização: teoria social e cultura global. Petrópolis(RJ): Vozes; 2000.

13. Ministério da Saúde (BR). Pré-natal e puerpério: atenção qualificada e humanizada. Manual técnico. Brasília (DF); 2005.

14. Freire P. Pedagogia do oprimido. Rio de Janeiro(RJ): Paz e Terra; 1987.

\section{Maria Celeste Landerdahl}

Universidade Federal de Santa Maria, Santa Maria/RS

\section{Lúcia Beatriz Ressel}

Universidade Federal de Santa Maria, Santa Maria/RS

\section{Fernanda Badineli Martins}

Secretaria de Município de Rosário do Sul/RS

\section{Fernanda Bheregaray Cabral}

Universidade Regional Integrada do Alto Uruguai e das Missões, Santiago/RS

\section{Mariam de Oliveira Gonçalves}

Universidade Federal de Santa Maria, Santa Maria/RS. 